CLINICAL STUDY

\title{
Functional characterization of naturally occurring NR3C2 gene mutations in Italian patients suffering from pseudohypoaldosteronism type 1
}

Antonio Balsamo, Alessandro Cicognani, Monia Gennari, Wolfgang G Sippell ${ }^{1}$, Soara Menabò, Federico Baronio and Felix G Riepe ${ }^{1}$

Division of Pediatric Endocrinology, Department of Pediatrics, Policlinico S. Orsola-Malpighi, University of Bologna, Via Massarenti 11, 40138 Bologna, Italy and ${ }^{1}$ Division of Pediatric Endocrinology, Department of Pediatrics, University Hospital Schleswig-Holstein, Campus Kiel, 24105 Kiel, Germany

(Correspondence should be addressed to A Balsamo; Email: antonio.balsamo@unibo.it)

\begin{abstract}
Objective: The renal form of pseudohypoaldosteronism type 1 (PHA1) is a rare disease caused by mutations in the human mineralocorticoid receptor gene (NR3C2).

Design: Aim of the study was to analyze the NR3C2 gene in three Italian patients with clinical signs of renal PHA1 and to evaluate the distribution of the $-2 \mathrm{G}>\mathrm{C}, \mathrm{c} .538 \mathrm{~A}>\mathrm{G}$, and c.722C $>\mathrm{T}$ single nucleotide polymorphism (SNP) pattern in the PHA1 patients and in 90 controls of the same ethnic origin.

Methods: Analysis of the NR3C2 gene sequence and of the polymorphic SNP markers. Functional characterization of the detected novel NR $3 \mathrm{C} 2$ mutations utilizing aldosterone-binding assays and reporter gene transactivation assays.

Results: One novel nonsense (Y134X) and one novel frameshift (2125delA) mutation were detected. They exhibited no aldosterone binding and no transactivation abilities. No mutation was detected in the third patient. Haploinsufficiency of NR3C2 was ruled out by microsatellite analysis in this patient. The c.722T SNP was detected in $97 \%$ of alleles in the Italian population which is significantly different from the general German or US population.

Conclusions: Molecular analysis of the NR3C2 gene in PHA1 patients is warranted to detect novel mutations in order to clarify the underlying genetic cause, which may extend the insight into relevant functional regions of the hMR protein. The effect the different distribution of the c.722T SNP is not clear to date. Further studies are necessary to provide evidence as to a possible advantage of a less sensitive hMR in southern countries.
\end{abstract}

European Journal of Endocrinology 156 249-256

\section{Introduction}

Aldosterone, the main mineralocorticoid hormone in humans, plays a central role in the regulation of volume and electrolyte homeostasis. Aldosterone acts through the hMR, a member of the nuclear receptor superfamily, which is a transcriptional factor that plays a part in the control of specific genes (1). It is structurally characterized by three distinct domains: an $\mathrm{N}$ terminal transcriptional activation domain, a central DNAbinding domain (DBD), and a $\mathrm{C}$ terminal ligand-binding domain (LDB). The latter performs multifunctional actions such as the interaction with heat-shock proteins, nuclear targeting, dimerization, and liganddependent transactivation function (1-3).

First described in 1958 by Cheek and Perry (4), pseudohypoaldosteronism type 1 (PHA1) is a rare, congenital disease characterized by neonatal presentation with dehydration and hyponatremia resulting from salt wasting, hypotension, and life-threatening hyperkalemia. Serum aldosterone and renin levels are elevated, and the patient fails to respond to treatment with mineralocorticoids. The term PHA1 refers to two different disorders that can be transmitted either with an autosomal recessive (arPHA1) or dominant (adPHA1) pattern of inheritance (5). The autosomaldominant form shares many of the same clinical features as the recessive form of the disease, including failure to thrive, salt loss, hyperkalemia, and metabolic acidosis despite elevated aldosterone and plasma renin activity (PRA) levels, but it is generally much milder in its course. Patients with adPHA1 normally require oral salt supplementation, but typically show a gradual clinical improvement with regard to renal salt loss during childhood. Some individuals are clinically asymptomatic but may have elevated PRA and aldosterone levels (5).

In most cases, adPHA1 is caused by mutations of the human mineralocorticoid receptor gene (NR3C2), which consists of 10 exons (6). To date, more than 20 
different PHA1-causing mutations in the NR3C2 gene have been described, including nonsense, frameshift, missense, and splice-site mutations distributed throughout the gene (6-14). In some patients with PHA1, especially with the sporadic form, no abnormalities in the gene for hMR were detected (14-16). It was speculated that polymorphisms in the NR3C2 gene may contribute to the phenotype although a major effect cannot be suggested from the in vitro data (17-19).

In this study, we analyzed a group of three children, all of Italian origin, who were examined for failure to thrive and vomiting during the first months of life. All presented with persistent hyponatremia and hyperkalemia, high levels of aldosterone and plasma renin activity. The analysis of the NR3C2 gene showed two novel mutations, one sporadic and one autosomal dominant in two patients. As no mutation was found in the third subject, an analysis of the polymorphic SNP markers was also performed, both in the patients and in the 90 healthy controls of the same ethnic origin, in order to evaluate their distribution pattern. In vitro functional studies on the NR3C2 gene variants containing the identified substitutions were then carried out in order to evaluate their role in salt losing disorders.

\section{Patients and methods}

\section{Patients}

Family 1. Patient 1, now 3.6 years old, is the only child in whom intrauterine growth retardation and fetal right kidney ptosis were documented by ultrasound examination. The risk of fetal distress led to a pre-term caesarean delivery at 36 weeks of gestation. Birth weight and length were $1695 \mathrm{~g}$ and $43 \mathrm{~cm}$ respectively. He was parenterally fed during the first weeks of life and, although the caloric intake was adequate, weight gain was poor until discharge (41 days, $2070 \mathrm{~g}$ ). A second inpatient admission at 56 days old was necessary because of recurrent vomiting and failure to thrive (weight and length $2310 \mathrm{~g}$ and $45 \mathrm{~cm}$ respectively). Hyponatremia $(118 \mathrm{mmol} / \mathrm{l})$ and hyperkalemia ( $6.5 \mathrm{mmol} / \mathrm{l}$ ) but no metabolic acidosis was documented. Plasma aldosterone ( $>2000 \mathrm{pg} / \mathrm{ml}(>5548 \mathrm{pmol} / \mathrm{l})$ : normal reference range for age, $140-1050 \mathrm{pg} / \mathrm{ml}(388-$ $2913 \mathrm{pmol} / \mathrm{l})$ ) and PRA were elevated ( $>45 \mathrm{ng} / \mathrm{ml}$ per $\mathrm{h}$, normal reference range for age 1.5-10.2 $\mathrm{ng} / \mathrm{ml}$ per $\mathrm{h}$ ). 17-Hydroxyprogesterone (170H-P), adrenocorticotropic hormone (ACTH), and cortisol were normal. After acute therapy with i.v. saline substitution, the infant showed marked catch-up growth with oral $\mathrm{NaCl}$ supplementation of $3 \mathrm{~g} /$ day. Plasma electrolytes remained normal under oral $\mathrm{NaCl}$ therapy, which is continued to date, but plasma aldosterone was sporadically elevated (Fig. 1). Both parents were clinically free of symptoms. The father's serum electrolytes and renin were normal but aldosterone level was slightly high (400 pg/ml (1109 pmol/l), normal reference range for age $80-300 \mathrm{pg} / \mathrm{ml}(222-832 \mathrm{pmol} / \mathrm{l}))$.

Family 2. Patient 2 is the second boy, now 3.2 years old. The pregnancy was uneventful and the delivery was a second caesarean delivery at term. Birth weight and length were $3020 \mathrm{~g}$ and $48 \mathrm{~cm}$ respectively. The infant was formula fed and presented at 21 days of age with failure to thrive and vomiting. On hospital admission, he showed hyponatremia $(120 \mathrm{mmol} / \mathrm{l})$ and hyperkalemia $(7.3 \mathrm{mmol} / \mathrm{l})$ with elevated aldosterone levels $(>$ $1600 \mathrm{pg} / \mathrm{ml}(>4438 \mathrm{pmol} / \mathrm{l}))$. Other parameters including plasma creatinine, ACTH, cortisol, and $17 \mathrm{OH}-\mathrm{P}$ were normal, as was ultrasound of the kidney. With $\mathrm{NaCl}$ supplementation given for 33 months he maintained electrolyte balance and showed marked weight gain $(13.1 \mathrm{~kg}$ ), although aldosterone (Fig. 1) and PRA levels tended to be high. Both the parents and the brother were free of symptoms and had normal aldosterone and PRA levels.

Family 3. Patient 3 is the first boy, now 3.8 years old, whose pregnancy was marked by a threatened miscarriage during the second trimester of gestation. Delivery was normal with a preterm (33 weeks) newborn of weight $2065 \mathrm{~g}$ and a length of $42 \mathrm{~cm}$. At the age of 18 days, he showed difficulties in gaining weight and hyponatremia $(126 \mathrm{mmol} / \mathrm{l})$ with normal K. Oral $\mathrm{NaCl}$ supplementation (17 mmol/day) was administered until discharge (at the age of 24 days, weight $2110 \mathrm{~g}$, Na $134 \mathrm{mmol} / \mathrm{l}$ ). Following repeated failure to suspend oral $\mathrm{NaCl}$ supplementation (serum Na 129 and 127, serum $\mathrm{K} 6.8$ and $6.9 \mathrm{mmol} / \mathrm{l}$ respectively), the hormonal examination showed very high aldosterone (8620 pg/ml (23 $911 \mathrm{pmol} / \mathrm{l})$ ) and PRA (38.8 ng/ml per h) levels. The patient was than treated with oral $\mathrm{NaCl}$ supplementation (ranging from 4 to $10 \mathrm{mmol} /$ day) with a satisfying growth rate, but with fluctuating aldosterone (Fig. 1) and PRA values. Both parents were clinically free of symptoms. The father's serum PRA was normal and his aldosterone level was slightly elevated (343 pg/ $\mathrm{ml}(951 \mathrm{pmol} / \mathrm{l}))$, whereas sodium and potassium were within the normal range. The mother showed a normally balanced aldosterone/PRA axis.

No consanguinity or events of prior electrolyte disturbance or inpatient treatment were recorded or recollected by the parents of the three families.

Healthy controls. To assess the PHA1 gene polymorphism frequency, 90 adult volunteers of Italian origin and 100 adult volunteers of German origin were 


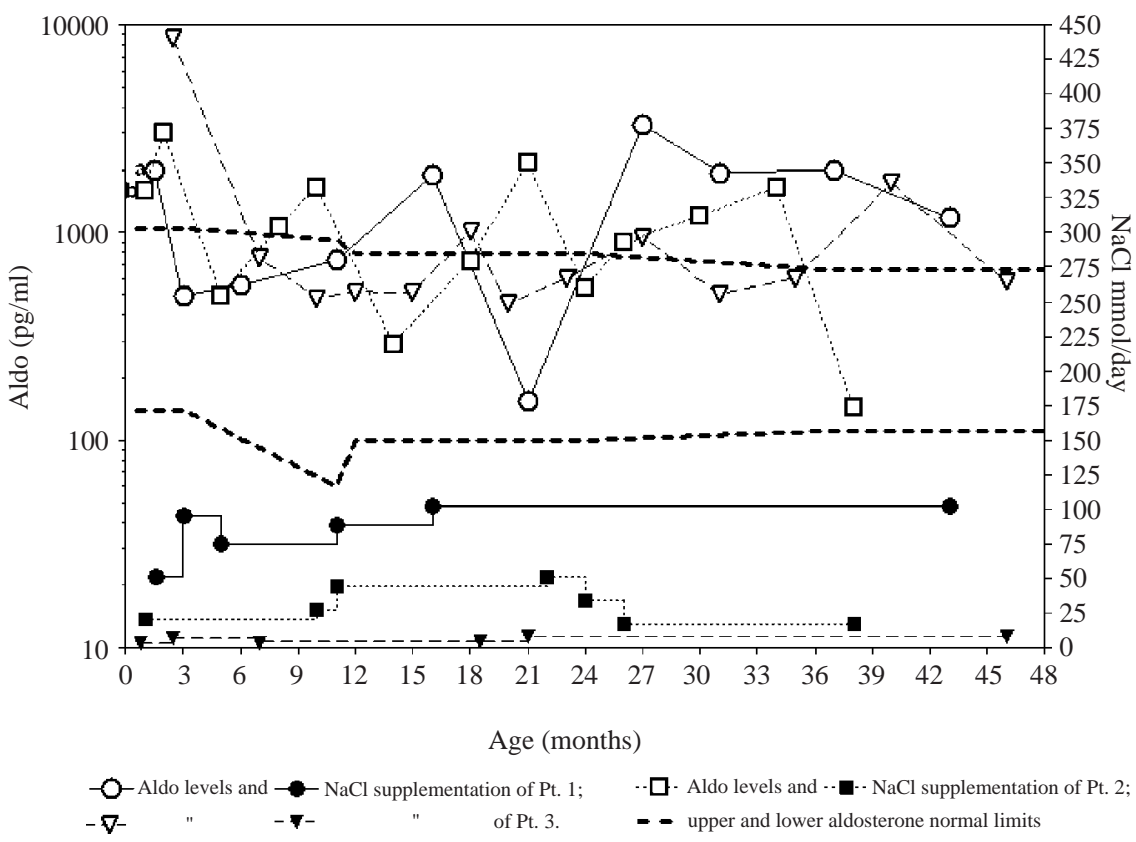

Figure 1 Levels of plasma aldosterone (pg/ml; multiply by 2.774 to transform in pmol/l) and $\mathrm{NaCl}$ supplementation in the three cases by age. The $a$ and $b$ points were arbitrarily plotted at 2000 and $1600 \mathrm{pg} / \mathrm{ml}$ scale respectively, although they do not represent the real aldosterone levels at diagnosis (the two original samples exceeded the higher detection level of the assay, but were not diluted to define their precise value).

used. Approval of the local ethics committee and informed consent were obtained beforehand.

\section{Methods}

Hormonal analysis. The following standard procedures were used to test the hormonal levels: aldosterone (RIA, Diagnostic System Laboratories, Webster, TX, USA), PRA (RIA, DIA-Sorin, Saluggia, VC, Italy), renin (Immuno-Chemiluminescent assay (ICMA) Nichols Institute Diagnostics, Bad Vilbel, Germany), cortisol (ICMA, Bayer Healthcare, East Walpole, MA, USA), ACTH (ICMA, Diagnostic Product Corporation DPC, Los Angeles, CA, USA), 17-OH-progesterone (RIA, Adaltis, Roma, Italia).

Mutational and SNP analysis. Blood samples for molecular genetic analysis were collected after informed consent from the parents or the healthy control population. Approval of the local ethics committee was obtained for the genomic studies. Genomic DNA was extracted from peripheral blood leukocytes, and the mineralocorticoid receptor gene (NR3C2) was amplified as described previously (8). The nucleotide sequences of the PCR products were directly determined using an automated fluorescence sequencer (ABI Prism 310 Genetic Analyzer, Perkin-Elmer, Wellesley, MA, USA). NR3C2 sequencing included all translated exons and the exon/intron boundaries in the case of PHA1 patients. Exon 2 was amplified and directly sequenced for the analysis of the polymorphic SNP markers in healthy controls. The NR3C2 cDNA (GenBank NM_000901) was used as template for analysis, numbering the A of the ATG translation initiation codon with +1 . The mutations were designated using the recommendations of the Nomenclature Working Group, whereupon the prefix c. indicates the cDNA sequence position (20). Microsatellite analysis was used to clarify the paternity and to investigate the possibility of haploinsufficiency due to allele loss in patient 3. The D4S1586, D4S3031, D4S3014, and D4S3008 microsatellite markers spanning a region of $3.2 \mathrm{cM}$ around the $N R 3 C 2$ gene were amplified by PCR, as described previously (21).

Construction of plasmids. The human full-length pRSNR3C2 DNA was kindly provided by RM Evans (Salk Institute, San Diego, CA, USA). A NR3C2-cDNA fragment was amplified by PCR and subcloned into the KpnI/XhoI site of a pcDNA3.1 expression vector (Invitrogen). The mutagenesis for c.402T $>$ A (Y134X) and c.2125delA (T709fs) was performed using the QuikChange XL site-directed mutagenesis kit (Stratagene, LaJolla, CA, USA; primers available on request). The introduction of the mutations was verified by sequencing the entire construct. 
In vitro expression and transactivation studies. Approximately, $2.5 \times 10^{5}$ African Green Monkey SV40-transformed kidney fibroblast cell line (COS-7) cells were grown in Dulbecco's modified Eagle's medium supplemented with glutamine and $10 \%$ fetal calf serum in 24-well plates. Transient transfection was performed $24 \mathrm{~h}$ after seeding using lipofectamine (Invitrogen) and $0.3 \mu \mathrm{g}$ pcDNA3.1 wild-type NR3C2 or pcDNA3.1 mutant $\mathrm{NR} 3 \mathrm{C} 2,0.3 \mu \mathrm{g}$ mouse mammary tumor virus (MMTV) luciferase reporter construct and $0.1 \mu \mathrm{g}$ pRLTK (Invitrogen) coding for renilla luciferase to normalize for the transfection efficiency. Aldosterone (Sigma) was added on the day after transfection for $24 \mathrm{~h}$ in different concentrations ranging from $10^{-12}$ to $10^{-6} \mathrm{~mol} / \mathrm{l}$. Firefly and renilla luciferase activity were detected with the dual luciferase assay (Promega) on a Veritas microplate luminometer (TurnerBiosystems, Sunnyvale, CA, USA). Protein analysis was performed using the Bradford method. Results were expressed as ratio of firefly luciferase activity over renilla luciferase activity over protein content. The effective dose for 50\% (ED50) was calculated using GraphPad Prism software version 4.0 (GraphPad Software, San Diego, CA, USA).

Protein studies. hMR proteins were obtained using the TNT Quick Coupled Transcription-Translation system (Promega). Plasmids coding for wild-type or mutant hMR were used as templates for transcription with T7 polymerase, followed by translation with either cold methionine for the binding studies or with ${ }^{35} \mathrm{~S}$ methionine $(1000 \mathrm{Ci} / \mathrm{mmol})$ for SDS-PAGE analysis. After electrophoresis, the SDS-polyacrylamide gels were dried and autoradiographed at $-80{ }^{\circ} \mathrm{C}$ overnight. Aldosterone binding characteristics were determined as previously described (22). Aliquots of in vitro translated hMR protein lysates were incubated with $\left[{ }^{3} \mathrm{H}\right]$ aldosterone in increasing concentrations $(0.25-8 \mathrm{nM})$ with or without an excess of unlabeled aldosterone for $4 \mathrm{~h}$ at $4{ }^{\circ} \mathrm{C}(n=3)$. Bound and unbound steroids were separated by the Dextran-coated charcoal method. Radioactivity from the bound fraction was counted in a LSC TRI-CARB 2300 TR liquid scintillation spectrometer (Packard, Dreieich, Germany). The $K_{\mathrm{d}}$ at equilibrium $\left(K_{\mathrm{D}}\right)$ of the wild-type hMR and the mutants was calculated using GraphPad Prism 4.0 software (GraphPad Software).

Statistics. For comparison of transactivation data and ANOVA on ranks test with a Tukey test as post hoc procedure for multiple comparisons versus the wild-type as control was utilized. A Fisher exact test was used to compare the allele frequency in the patient and control groups.

\section{Results}

\section{Mutational and SNP analysis}

NR3C2 gene analysis of patient 1 and his father revealed a novel nonsense mutation changing thymidine at nucleotide 402 in exon 2 to adenine (c.402T $>$ A). The mother showed a wild-type sequence at this position. The mutation causes a change of tyrosine 134 to a premature stop codon (Y134X) leading to a truncated $\mathrm{N}$ terminus and an absent DBD and LBD. A heterozygous deletion of adenine at nucleotide position 2125 in exon 5 (c.2125delA) was detected in the NR3C2 gene of patient 2. His parents displayed a wildtype sequence at this position. The mutation causes a frameshift starting at amino acid T709 resulting in a putative premature stop codon at amino acid 772 (L772X) (Fig. 2). No novel or known sequence variation besides homozygosity for the SNPs $-2 \mathrm{G}$, c.538A, c. $722 \mathrm{~T}$ was detected in patient 3 . The parents of patient 3 were also homozygous for c.538A and c.722T but heterozygous for $-2 \mathrm{G}>\mathrm{C}$. The results of the microsatellite analyses indicated that paternity was highly likely in every family and ruled out the possibility of haploinsufficiency in patient 3 (Fig. 3). The distribution of the NR3C2 SNP pattern in the PHA1 patients and the distribution of the three NR3C2 SNPs in the healthy control populations are shown in Table 1. The frequency of the SNPs in the PHA1 patients appeared

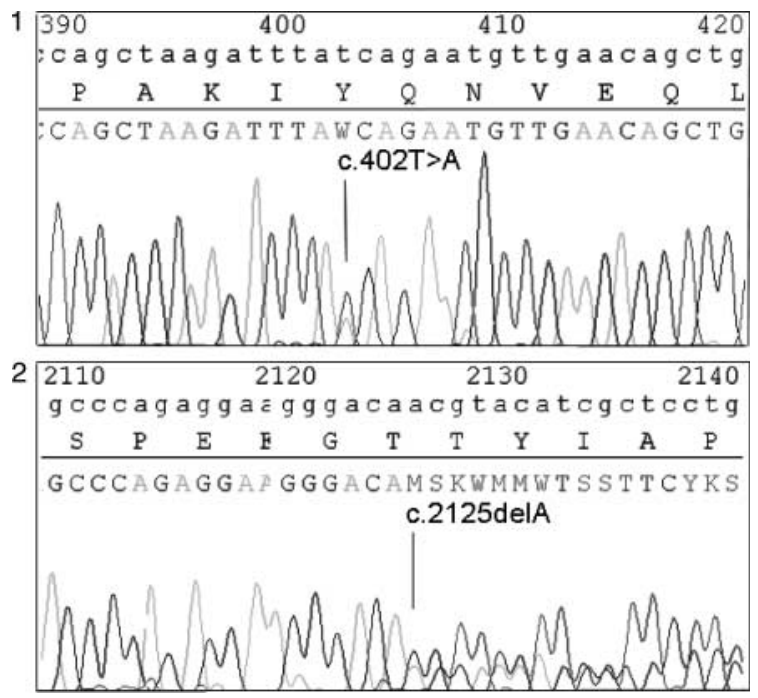

Figure 2 NR3C2 mutations. Mutation analysis by direct DNA sequencing: 1 , nonsense mutation changing thymidine at nucleotide 402 in exon 2 to adenine (c.402T > A) detected in patient 1. The mutation causes a change of tyrosine 134 to a premature stop codon (Y134X). 2, Heterozygous deletion of adenine at nucleotide position 2125 in exon 5 (c.2125delA) detected in patient 2. The mutation causes a frameshift starting at amino acid T709R resulting in a putative premature stop codon at amino acid 772 (L772X). The NR3C2 cDNA (GenBank NM_000901) was used as template for analysis, numbering the A of the ATG translation initiation codon with +1 . 

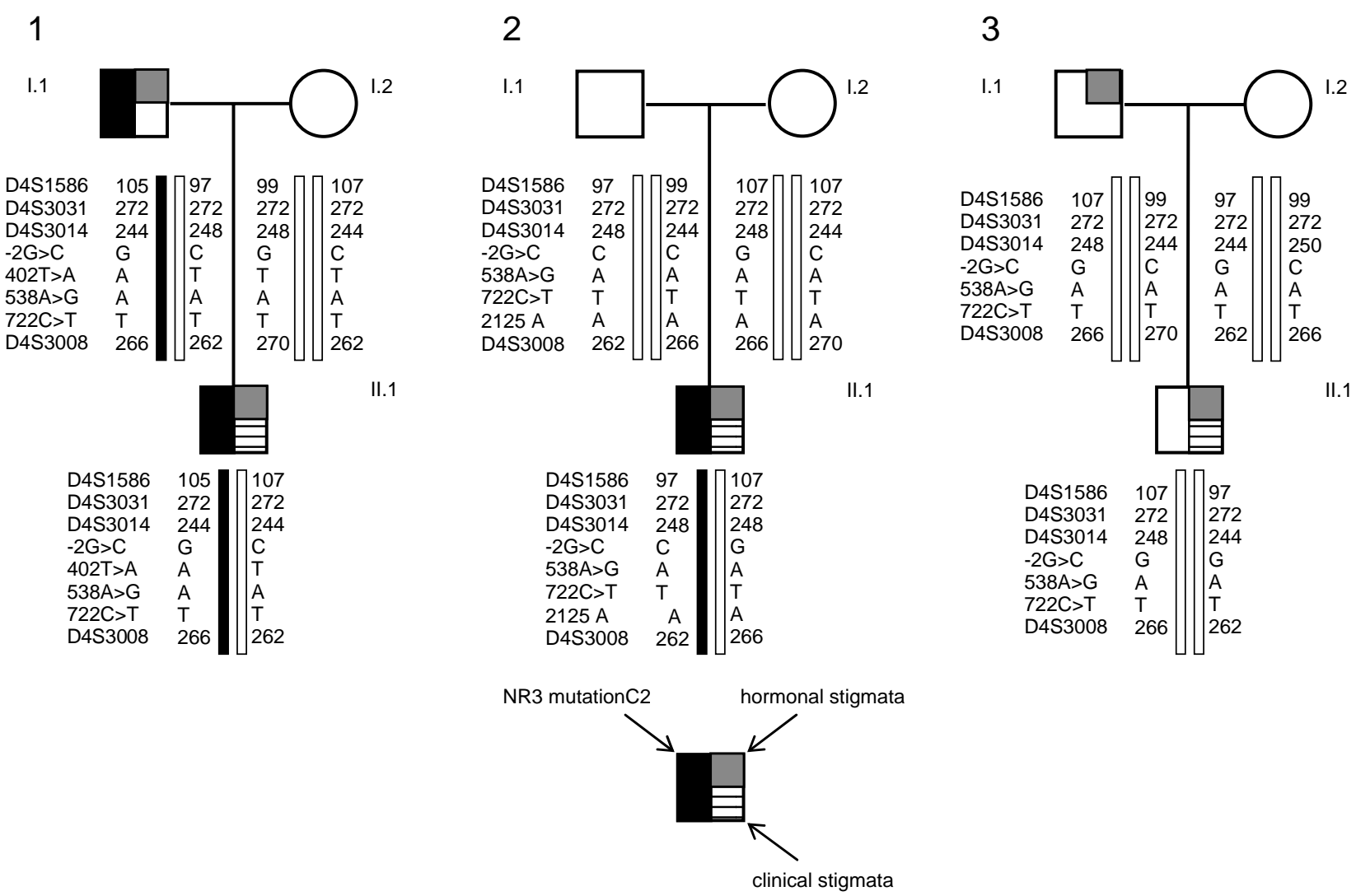

Figure $3 \mathrm{PHA} 1$ pedigrees and microsatellite distribution. The NR3C2 mutations are depicted as black boxes in the pedigree, probands with hormonal stigmata carry a grey box, and individuals with a clinical phenotype are depicted with a striped box. Genotypes for markers D4S1586, D4S3031, D4S3014, and D4S3008, NR3C2 gene polymorphisms - 2G > C, 538A > G (I180V), and 722C > T (A241V) are displayed in relation to the $h M R$ gene. The disease-associated haplotype is indicated by black bars.

not to differ significantly from the Italian control alleles $(P>0.05)$.

\section{In vitro expression and transactivation}

Aldosterone induced a dose-dependent transactivation by wild-type hMR on a MMTV reporter reaching a plateau at $10^{-8} \mathrm{~mol} / \mathrm{l}$ aldosterone. The ED50 value was calculated as $6.5 \times 10^{-11} \pm 1.4 \times 10^{-11} \mathrm{~mol} / \mathrm{l}$. The mutant hMR proteins showed no measurable transactivation with the MMTV reporter construct. Co-transfection experiments were performed with the wild-type hMR and the mutant proteins to rule out a dominant negative effect of the mutations. Using equimolar concentrations of each hMR construct, the transactivation induction at $10^{-10} \mathrm{~mol} / \mathrm{l}$ aldosterone was similar for Y134X-hMR or T709fs-hMR co-transfected with wild-type hMR compared with wild-type hMR alone (data not shown).

\section{Protein studies}

Protein translation of the wild-type hMR receptor and the mutant Y134X-hMR and T709fs-hMR was studied in vitro by SDS-PAGE analysis (Fig. 4). The wild-type and T709fs-hMR mutant showed similar in vitro translation levels, whereas the Y134X-hMR mutant presented a weaker band. A band of approximately $100 \mathrm{kDa}$ was detected for the wild-type hMR, whereas the fragment representing the frameshift mutant T709fs-hMR had a size of approximately $80 \mathrm{kDa}$. The fragment resulting from the nonsense mutant Y134X-hMR was translated with an expected size of approximately $15 \mathrm{kDa}$ but the intensity was much weaker, suggesting unstable RNA generation. No additional bands were detected with the translation of the hMR mutants. The ability of wild-type and mutant hMR proteins to bind aldosterone was studied in vitro using a Scatchard plot. The $K_{\mathrm{D}}$ of the wild-type hMR protein was $3.2 \pm 0.2 \mathrm{nmol} / \mathrm{l}$ (mean \pm s.e.m.) under the experimental conditions. The mutants Y134X-hMR and T709fs-hMR showed a complete absence of aldosterone binding.

\section{Discussion}

We investigated the NR3C2 gene in three unrelated Italian families with the clinical diagnosis of PHA1. Two novel heterozygous mutations in the $\mathrm{NR} 3 \mathrm{C} 2$ gene were 
Table 1 SNP distribution in pseudohypoaldosteronism type 1 patients, the Italian, German and US population.

\begin{tabular}{lcccc}
\hline & $\begin{array}{c}\text { NR3C2 } \\
-\mathbf{2 G}>\mathbf{C} \\
\text { alleles } \\
\text { rs2070951 }\end{array}$ & $\begin{array}{c}\text { NR3C2 } \\
\text { c.538A }>\text { G } \\
\text { alleles } \\
\text { rs5522 }\end{array}$ & $\begin{array}{c}\text { NR3C2 c. } \\
\text { (22C }>\text { T alleles } \\
\text { Chr4:149576741 }\end{array}$ \\
\hline PHA1 patients & $\mathrm{N}$ & 2 & 0 & 6 \\
Alleles =6 & $\%$ & 33 & 0 & 100 \\
Italian controls & $\mathrm{N}$ & 77 & 9 & 174 \\
Alleles =180 & $\%$ & 43 & 5 & 97 \\
German controls & $\mathrm{N}$ & 56 & 10 & 56 \\
Alleles =200 & $\%$ & $28^{*}$ & 5 & $28^{*}$ \\
German controls (19) & $\mathrm{N}$ & 39 & 17 & 0 \\
Alleles =100 & $\%$ & 39 & $17^{\star}$ & $0^{\star}$ \\
US controls (17) & $\mathrm{N}$ & $\mathrm{ND}$ & 11 & 62 \\
Alleles =100 & $\%$ & - & 11 & $62^{*}$ \\
\hline
\end{tabular}

$\mathrm{N}$, number; ND, not detected; \%, percentage, ${ }^{\star} P<0.01$ for the difference between Italian controls and other groups.

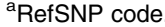

${ }^{\mathrm{b}}$ Chromosomal localisation.

identified. The nonsense mutation Y134X is localized in exon 2, corresponding to the $\mathrm{N}$ terminal protein domain. We were able to show that the hMR protein is severely truncated due to the localization of the premature stop codon. The complete DNA and hormone-binding domain is lost (23). It is a well known, but rare event in nuclear receptors that

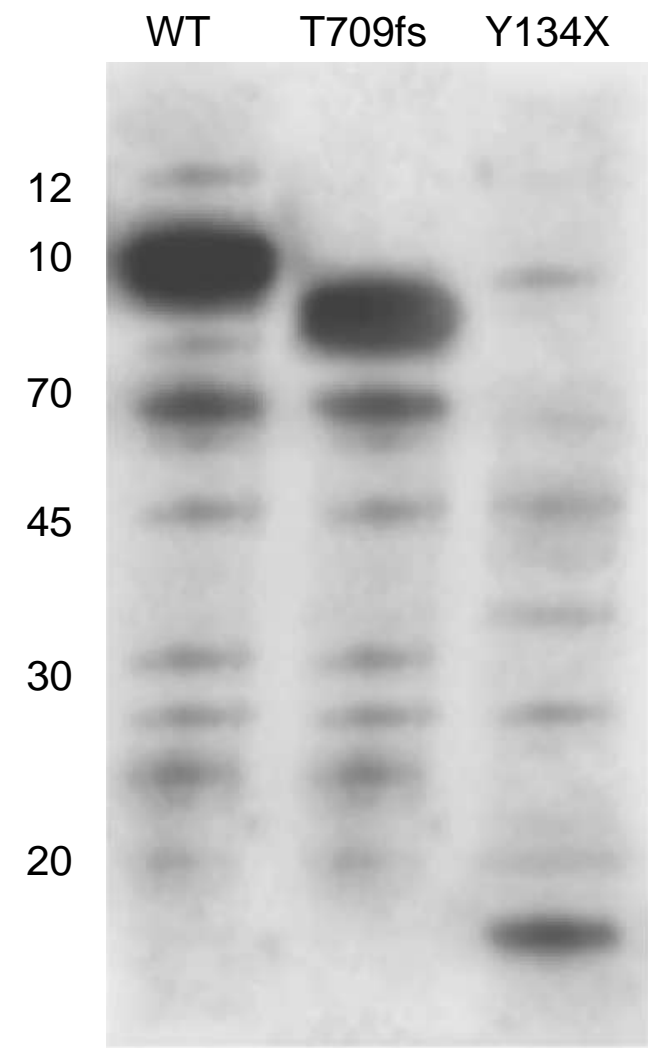

Figure 4 In vitro transcription and translation of wild-type and mutant $\mathrm{hMRs}$. After in vitro transcription and translation with ${ }^{35} \mathrm{~S}$-methionine $(1000 \mathrm{Ci} / \mathrm{mmol})$, the wild-type and mutant hMRs were analyzed by $12.5 \%$ SDS-PAGE. Molecular weight indicated on the left. alternative translation initiation codons can be utilized in case of $\mathrm{N}$ terminal nonsense mutations (24). There are several ATG nucleotides in frame with the wild-type hMR protein which may be candidates for such an event. But obviously this phenomenon is not observed with the $\mathrm{Y} 134 \mathrm{X}$ mutation in hMR as no additional bands have been detected in the PAGE analysis and no transactivation was achieved. The reason for that is most likely the lack of a strong transcription promoting Kozak sequence upstream of the ATG nucleotides (25). The second mutation is a frameshift caused by one basepair deletion (2125delA). The frameshift mutation is localized in exon 5 coding for the hormone-binding domain region. The protein sequence and structure is severely disturbed starting at residue T709. Due to the putative premature stop codon at amino acid 772, the mutation leads furthermore to a truncation of the LBD. This was shown in the PAGE analysis. In vitro expression studies provided definitive confirmation of the deleterious effect of the mutations to receptor function as both sequence variations produce proteins, which could neither bind aldosterone nor enhance the aldosteronedependent transactivation activity. Both proteins exhibited no dominant negative effect on the wild-type hMR protein. Therefore, haploinsufficiency of the hMR locus is sufficient to cause PHA1 in these two cases.

The DNA analysis of the parents to patient 1 showed the presence of the Y134X mutation on the paternal allele. However, the father had no history of clinical PHA1 manifestation and had normal plasma electrolytes and renin value with only a slightly elevated aldosterone level at testing. The finding that parents carrying the same mutation as the index cases, have no symptomatic manifestation, recurs in many reports of autosomal dominant forms of PHA1 (9, 10). As postulated by Geller (6) and Tajima (10), it is possible that not only mutations in the NR3C2 gene, but also either mutations in additional genes or non-genetic factors may contribute to clinical and biochemical phenotypes of the carriers of NR3C2 mutations. Several attempts were started to pin down these additional genes or factors without any success $(8,18,26-28)$. A possible difference in disease expression might be explained by a different distribution of NR3C2 polymorphisms minimally affecting the hMR function (18). However, the studied NR3C2 polymorphisms were similarly arranged in both the PHA1 patient and the healthy father. Although the shorter duration of the pregnancy in the index case (36 weeks) compared with the father (40 weeks) might have some influence on the salt homeostasis directly after birth, we assume that this may not be the only cause for their differential clinical presentation. Additional non-genetic factors influencing the salt conservation could not be re-collected. The mutation in patient 2 turned out to be a de novo or sporadic mutation because it was not present on the NR3C2 gene of the parents. De novo mutations are not infrequent in autosomal dominant PHA1, although one 
might take into account that the paternity is not always confirmed on the genetic level $(12,14)$. We also have to make this limitation for our family to some degree as only the distribution of microsatellite markers within the NR3C2 locus was investigated and no complete paternity test has been performed.

Patient 3 does not present any mutations in the coding exons of $\mathrm{NR} 3 \mathrm{C} 2$ and the intron/exon splice junctions. Haploinsufficiency of the NR3C2 locus as the reason for the PHA1 phenotype was also ruled out by microsatellite analysis. In several studies of both dominant and sporadic forms, it was not possible to detect mutations in or deletions of the NR3C2 gene (12, $14,16)$. However, as in our case, the presence of mutations in the regulatory regions of the NR $3 C 2$ gene, which were not analyzed in this study, cannot be excluded. Alternatively, it can be speculated that additional genes are involved in the pathogenesis of PHA1 in this patient. Arai et al. (18) have proposed that naturally occurring polymorphisms in the NR3C2 gene could negatively influence the salt conservation. In particular, Arai et al. (18) studied one regulatory and two non-synonymous SNPs in the NR3C2 gene $(-2 \mathrm{G}>\mathrm{C}$, c. $538 \mathrm{~A}>\mathrm{G}$, and c.722C $>\mathrm{T}$ SNPs), which had previously been reported to occur in the general population $(16,19)$. The results suggested that each of them was functionally and structurally heterogeneous with a possible mild interference on normal salt conservation. We therefore checked the distribution of these SNPs in patient 3 and compared it with the healthy Italian population. However, the patient showed no special arrangement of these SNPs in comparison to the controls. We therefore cannot explain the phenotype by this. Still, it might be possible that these SNPs influence hMR function in case of co-occurrence of additional sequence variations in other genes or in case of environmental hazards disrupting salt conservation.

Taking this hypothesis into account, it is very surprising to note that major differences in the allele frequency of the c.722T SNP were found in the Italian population, in the German population investigated in this study, in the German collective tested by Ludwig et al. and in the US population studied by Arai et al. (16, 17, 19). The c.722T SNP appeared to be the wild-type condition in Italy, but was present to a significantly lesser extent in the German population (19) and in the US population (17) (Table 1). A possible effect of a less sensitive hMR in the Italian population would be lower blood pressure with normal salt intake or normal blood pressure with high salt intake. One may speculate that this would account for a possible advantage of survival for Italians and perhaps other southern populations. It is known that the Mediterranean diet can reduce the risk of hypertension and coronary heart disease (29, 30). However, the INTERSALT study revealed no differences in the daily salt intake or the mean blood pressure between the US, Germany, and Italy (31-33). It therefore remains obscure whether the differences in NR3C2 gene SNP distribution have any effect on sodium homeostasis.

In conclusion, we were able to clarify the underlying molecular cause of PHA1 in two Italian patients. The reason for the PHA1 in the third patient remains obscure. The molecular analysis of the NR3C2 gene in PHA1 patients is warranted to clarify the underlying genetic cause, to open the way for genetic counseling, to be able to withdraw sodium supplementation after infancy and to detect novel mutations, which may increase our insight into relevant functional regions of the hMR protein. The role of functional polymorphisms of the NR3C2 gene, if any, is still unclear but might be disease-supporting in the case of co-occurring genetic or environmental stressors. The impact of the lower frequency of the c.722T SNP in northern Europe and the US compared with Italy is therefore totally unclear.

\section{Acknowledgements}

We are grateful to Maurizio Maccaferri, Giuseppe Cangemi, Gila Hohmann, and Tanja Dahm for their technical assistance. We also thank the nurses Domenica Sarli and Sandra Sita for their help in the blood samples collection and storage for PHA1 gene polymorphisms.

\section{References}

1 Evans RM. The steroid and thyroid hormone receptor superfamily. Science 1988240 889-895.

2 Ham J \& Parker MG. Regulation of gene expression by nuclear hormone receptors. Current Opinion in Cell Biology 19891 503-511.

3 Arriza JL, Weinberger C, Cerelli G, Glaser TM, Handelin BL, Housman DE \& Evans RM. Cloning of human mineralocorticoid receptor complementary DNA: structural and functional kinship with the glucocorticoid receptor. Science 1987237 268-275.

4 Cheek D \& Perry J. A salt wasting syndrome in infancy. Archives of Disease in Childhood $195833252-256$.

5 Hanukoglu A. Type I pseudohypoaldosteronism includes two clinically and genetically distinct entities with either renal or multiple target organ defects. Journal of Clinical Endocrinology and Metabolism 199173 936-944.

6 Geller DS, Rodriguez-Soriano J, Vallo Boado A, Schifter S, Bayer M, Chang SS \& Lifton RP. Mutations in the mineralocorticoid receptor gene cause autosomal dominant pseudohypoaldosteronism type I. Nature Genetics 199819 279-281.

7 Geller DS, Zhang J, Zennaro MC, Vallo-Boado A, RodriguezSoriano J, Furu L, Haws R, Metzger D, Botelho B, Karaviti L, Haqq AM, Corey H, Janssens S, Corvol P \& Lifton RP. Autosomal dominant pseudohypoaldosteronism type 1: mechanisms, evidence for neonatal lethality, and phenotypic expression in adults. Journal of the American Society of Nephrology 200617 1429-1436.

8 Riepe FG, Krone N, Morlot M, Ludwig M, Sippell WG \& Partsch CJ. Identification of a novel mutation in the human mineralocorticoid receptor gene in a german family with autosomal-dominant pseudohypoaldosteronism type 1: further evidence for marked interindividual clinical heterogeneity. Journal of Clinical Endocrinology and Metabolism $2003 \mathbf{8 8} 1683-1686$.

9 Riepe FG, Krone N, Morlot M, Peter M, Sippell WG \& Partsch CJ. Autosomal-dominant pseudohypoaldosteronism type 1 in a 
Turkish family is associated with a novel nonsense mutation in the human mineralocorticoid receptor gene. Journal of Clinical Endocrinology and Metabolism 200489 2150-2152.

10 Tajima T, Kitagawa H, Yokoya S, Tachibana K, Adachi M, Nakae J, Suwa S, Katoh S \& Fujieda K. A novel missense mutation of mineralocorticoid receptor gene in one Japanese family with a renal form of pseudohypoaldosteronism type 1. Journal of Clinical Endocrinology and Metabolism 200085 4690-4694.

11 Nystrom AM, Bondeson ML, Skanke N, Martensson J, Stromberg B, Gustafsson J \& Anneren G. A novel nonsense mutation of the mineralocorticoid receptor gene in a Swedish family with pseudohypoaldosteronism type I (PHA1). Journal of Clinical Endocrinology and Metabolism 200489 227-231.

12 Sartorato P, Khaldi Y, Lapeyraque AL, Armanini D, Kuhnle U, Salomon R, Caprio M, Viengchareun S, Lombes M \& Zennaro MC. Inactivating mutations of the mineralocorticoid receptor in Type I pseudohypoaldosteronism. Molecular and Cellular Endocrinology 2004217 119-125.

13 Sartorato P, Lapeyraque AL, Armanini D, Kuhnle U, Khaldi Y, Salomon R, Abadie V, Di Battista E, Naselli A, Racine A, Bosio M, Caprio M, Poulet-Young V, Chabrolle JP, Niaudet P, De Gennes C, Lecornec MH, Poisson E, Fusco AM, Loli P, Lombes M \& Zennaro MC. Different inactivating mutations of the mineralocorticoid receptor in fourteen families affected by type I pseudohypoaldosteronism. Journal of Clinical Endocrinology and Metabolism 200388 2508-2517.

14 Viemann M, Peter M, Lopez-Siguero JP, Simic-Schleicher G \& Sippell WG. Evidence for genetic heterogeneity of pseudohypoaldosteronism type 1: identification of a novel mutation in the human mineralocorticoid receptor in one sporadic case and no mutations in two autosomal dominant kindreds. Journal of Clinical Endocrinology and Metabolism 200186 2056-2059.

15 Zennaro MC, Borensztein P, Jeunemaitre X, Armanini D \& Soubrier F. No alteration in the primary structure of the mineralocorticoid receptor in a family with pseudohypoaldosteronism. Journal of Clinical Endocrinology and Metabolism 199479 32-38.

16 Arai K, Tsigos C, Suzuki Y, Listwak S, Zachman K, Zangeneh F, Rapaport R, Chanoine JP \& Chrousos GP. No apparent mineralocorticoid receptor defect in a series of sporadic cases of pseudohypoaldosteronism. Journal of Clinical Endocrinology and Metabolism $1995 \mathbf{8 0} 814-817$.

17 Arai K, Tsigos C, Suzuki Y, Irony I, Karl M, Listwak S \& Chrousos GP. Physiological and molecular aspects of mineralocorticoid receptor action in pseudohypoaldosteronism: a responsiveness test and therapy. Journal of Clinical Endocrinology and Metabolism 199479 1019-1023.

18 Arai K, Nakagomi Y, Iketani M, Shimura Y, Amemiya S, Ohyama K \& Shibasaki T. Functional polymorphisms in the mineralocorticoid receptor and amirolide-sensitive sodium channel genes in a patient with sporadic pseudohypoaldosteronism. Human Genetics 2003112 91-97.

19 Ludwig M, Bolkenius U, Wickert L \& Bidlingmaier F. Common polymorphisms in genes encoding the human mineralocorticoid receptor and the human amiloride-sensitive sodium channel. Journal of Steroid Biochemistry and Molecular Biology $19986 \mathbf{6 4}$ 227-230.

20 Den Dunnen JT \& Antonarakis SE. Nomenclature for the description of human sequence variations. Human Genetics 2001 109 121-124.
21 Fernandes-Rosa FL, De Castro M, Latronico AC, Sippell W, Riepe FG \& Antonini SR. Recurrence of the R947X mutation in unrelated families with autosomal dominant pseudohypoaldosteronism type 1: evidence for a mutational hot spot in the mineralocorticoid receptor gene. Journal of Clinical Endocrinology and Metabolism 200691 3671-3675.

22 Quinkler M, Meyer B, Bumke-Vogt C, Grossmann C, Gruber U, Oelkers W, Diederich S \& Bahr V. Agonistic and antagonistic properties of progesterone metabolites at the human mineralocorticoid receptor. European Journal of Endocrinology 2002146 789-799.

23 Beato M, Chalepakis G, Schauer M \& Slater EP. DNA regulatory elements for steroid hormones. Journal of Steroid Biochemistry $198932737-747$.

24 Ozisik G, Mantovani G, Achermann JC, Persani L, Spada A, Weiss J, Beck-Peccoz P \& Jameson JL. An alternate translation initiation site circumvents an amino-terminal DAX1 nonsense mutation leading to a mild form of X-linked adrenal hypoplasia congenita. Journal of Clinical Endocrinology and Metabolism 200388 417-423.

25 Kozak M. Point mutations define a sequence flanking the AUG initiator codon that modulates translation by eukaryotic ribosomes. Cell 198644 283-292.

26 Arai K, Zachman K, Shibasaki T \& Chrousos GP. Polymorphisms of amiloride-sensitive sodium channel subunits in five sporadic cases of pseudohypoaldosteronism: do they have pathologic potential? Journal of Clinical Endocrinology and Metabolism 1999 $842434-2437$.

27 Ludwig M, Bidlingmaier F \& Reissinger A. Pseudohypoaldosteronism type 1 and the genes encoding prostasin, alpha-spectrin, and Nedd4. International Journal of Molecular Medicine 200414 1101-1104.

28 Huey CL, Riepe FG, Sippell WG \& Yu AS. Genetic heterogeneity in autosomal dominant pseudohypoaldosteronism type I: exclusion of claudin-8 as a candidate gene. American Journal of Nephrology 200424 483-487.

29 Srinath Reddy K \& Katan MB. Diet, nutrition and the prevention of hypertension and cardiovascular diseases. Public Health Nutrition 20047 167-186.

30 Jossa F \& Mancini M. The Mediterranean diet in the prevention of arteriosclerosis. Recenti Progressi in Medicina 199687 175-181.

31 Intersalt: an international study of electrolyte excretion and blood pressure. Results for 24 hour urinary sodium and potassium excretion. Intersalt Cooperative Research Group. British Medical Journal 1988297 319-328.

32 Anon. Blood pressure and relative body weight, alcohol consumption and electrolyte excretion in the FRG and the GDR: the Intersalt Study. The Intersalt Study Group form the FRG and the GDR. Klinische Wochenschrift $19906 \mathbf{6 8}$ 655-663.

33 Elliott P, Stamler J, Nichols R, Dyer AR, Stamler R, Kesteloot H \& Marmot M. Intersalt revisited: further analyses of 24 hour sodium excretion and blood pressure within and across populations. Intersalt Cooperative Research Group. British Medical Journal 1996 312 1249-1253.

Received 29 August 2006

Accepted 7 November 2006 